\title{
Using a creativity test standardized on a Hungarian sample to identify high creative abilities of socially disadvantaged students
}

DOI: $10.46932 / \mathrm{sfjdv2n2-102}$

Received in: March 1st, 2021

Accepted in: May 30th, 2021

\author{
Rákóczi, Emese \\ clinical psychologist \\ Institution: National Talent Centre \\ Budapest, Váci út 49, H-1134 \\ Szitó, Imre \\ educational psychologist \\ Institution: National Talent Centre \\ Budapest, Váci út 49, H-1134 \\ E-mail: imre.szito@gmail.com
}

\begin{abstract}
Although there is no consensus about the nature of the connection between creativity and divergent thinking, divergent thinking is an important indicator of creative abilities. Creativity is an important characteristic of the diversity of giftedness that contains general and domain specific manifestations. The MONDALK Test measuring divergent thinking was developed in Hungary utilizing and furthering the principles of Wallach-Kogan Creativity Tests (WKCT) and standardized on a representative sample of 1219 students aged 7-18. The results of the confirmatory factor analysis show that the A and B versions of the three subtests of the test measure a unified construct of the related visual, linguistic and productivity focused domains that also differ in domain-specific characteristics. In gifted identification, test bias against socially disadvantaged students and students at the risk of school dropout can only be eliminated if we use an 80th percentile cut-off point of originality and quality of originality measures instead of the usual 90th percentile cut-off point.
\end{abstract}

Key words: measurement of creativity, high creative ability, disadvantaged students, test bias, identification of gifted

\section{INTRODUCTION}

Creativity is an important characteristic of the diversity of giftedness that contains general and domain specific manifestations (Kaufman et al., 2009; An \& Runco, 2016). Evidence-based research shows that gifted identification can only be successful if the identification process utilizes methods aimed at several domains of giftedness (multitrait) with several methods examining a certain domain (multimethod) (Geiser et al., 2015; García et al., 2021a). An important alternative to using different types of methods is to measure creative abilities with tests. Divergent thinking and productive imagination are key aspects of creative abilities (Runco, 2014). Solutions of a problem are considered creative if they are original, but not only in the sense of being extremely novel - they are also innovative and offer unusual 
answers reflecting the needs of the social context where the problem emerged. In the process of problemsolving, the emergence of creative answers is facilitated by intrinsic motivational state, while through the steps leading to problem solution, domain-specific information is organized by heuristics within an original learning style that give space to unusual attempts (Amabile, 1983, 2013).

Although there is no consensus about the nature of the connection between creativity and divergent thinking, divergent thinking is an important indicator of creative abilities (Baer, 2011; Runco \& Acar, 2012; Said-Metwaly et al., 2017). Although not all students identified as divergent thinkers will realize creative achievement permanently, this dilemma is mostly the problem of the interaction between talent development and learning environment as in the interaction between the individual and the environment. Those theories of giftedness that put an emphasis on the developmental aspect and gifted potential treat creative abilities and creative performance as different entities until the end of adolescence, pointing out that abilities emerging at a certain age only become skills later (Gagné, 2004; Runco, 2014). If waiting for and focusing only on students' creative achievements we fail to identify their abilities and give up on potentially gifted students whose motivational, self-esteem issues or social disadvantages discourage them from completing creative products.

\subsection{MEASURING DIVERGENT THINKING}

Well-known creativity tests measuring divergent thinking are the Wallach-Kogan Creativity Tests (WKCT) and the Torrance Tests of Creative Thinking (TTCT) (Wallach \& Kogan, 1965; Torrance, 1990; Barkóczi \& Zétényi, 1981). It uses the principles and task types of the WKTC, the subtest of which are: 1. Instances, 2. Alternate uses, 3. Similarities, 4. Pattern Meanings, 5. Line Meanings. Although TTCT is more widespread across the world, using WKTC received encouragement in the past decades from computer applications (Lau, Cheung, 2010; Pásztor et al., 2015).

Most frequently used measures of tests assessing divergent thinking are fluency, flexibility, and originality. TTCT also uses elaboration, abstractness of titles and resistance to premature closure (Torrance, 1990). Several researchers questioned - based mostly on correlation analysis and exploratory factor analysis - whether the measures were independent factors, and they argued that in spite of the several measures, TTCT in fact only measures one factor, which has a great impact on the interpretation of the measures (Runco, 1986; Heausler et al., 1988). Further research using confirmatory factor analysis confirmed that the above measures have a strong correlation within the factor but eventually create at least two factors: an innovative and an adaptive factor (Kim et al., 2006; Krumm et al., 2016). The innovative factor contains fluency and originality, while elaboration, abstractness of titles and resistance to premature closure are part of the adaptive factor (Kim, 2005; Kim et al., 2006; Krumm et al., 2016). The 
independence and correlation of the measures mentioned above were considered when selecting the measures and evaluating the tasks of the new test.

\section{MATERIALS AND METHODS}

\subsection{MONDALK TEST WITH NEW TASK TYPES AND TASKS}

The development of the MONDALK Test measuring divergent thinking utilized and furthered the principles of Wallach-Kogan Creativity Tests (WKCT) creating new task-types and tasks organized into three subtests. The test battery has the following subtests: 1. Image meanings - containing eight tasks based on the principles of the Pattern meanings and Line meanings subtests of WKTC. 2. Sentence generation - a verbal linguistic task in which two reoccurring words have to be re-combined and put into context by generating sentences; this tasks needs mostly imagination as in the definition of creativity in contrast to the Instances subtest of WKTC which mostly needs memory elements; this subtest has three tasks. 3. Function searching - Alternate uses and Unusual Uses of WKTC and TTCT can be viewed as its antecedents, there are four tasks in this subtest. The subtests of the test can be administered in the order presented above in an individual situation by a psychologist trained to use the test. The instruction of the test emphasizes that the student should use his/her imagination and come up with multiple possibilities. All answers to the tasks are verbal, the time limit of the subtests are 8, 9, and 12 minutes, altogether 30 minutes. With students age 7-10 test administration is interactive: the answers are written down by the psychologist, while in the age-range of 11-18 years, students write their own answers on the test sheets.

\subsection{STANDARDIZATION SAMPLE}

The sample of 1219 students is representative according to Hungary's regions, settlement types, types of school, gender and age. The sample size of version A of the test is 606, that of version B is 613 . Both versions have 6 age groups with at least 100 students in each group. In both versions the age groups are: 7-8, 9-10, 11-12, 13-14, 15-16, 17-18 years.

There were 58 socially disadvantaged (SD) students, and 84 students at the risk of school dropout in the total sample. In Hungary, socially disadvantaged students are identified by the Public Education Act as a low income per capita of the family, parents' low level of education, permanent unemployment, and poor living conditions. The risk of becoming a school dropout is defined by the Public Education Act as the overall average of the learner's grades (on a five-point scale) stagnating under 2.5 at least throughout one semester (low achievement). 


\subsection{MEASURES AND SCORING}

The quantitative evaluation of a subtest tasks utilizes two measures: originality and quality of originality. The measures belonging to adaptive factors as described by Kim et al. (2006) are not applicable because of the nature of the tasks. As originality and fluency shows high correlation in the innovative factor (Kim, 2005; Kim et al., 2006; Krumm et al., 2016) only originality measures were deemed as sufficiently informative to form norms for the new test. To enforce the answers of students who had a low fluency but high originality, a measure of quality of originality was calculated. When defining the formula regarding the quality of originality, similar initiatives of other researchers were taken into account and care was taken to ensure that the measure should be in harmony with the basic construct of the test (Dixon, 1979; Paulus et al., 2011). The formulas for calculating the measures are:

$$
\begin{gathered}
\text { Originality }_{\text {subtest }}=\sum \text { originality }_{\text {task }} \\
\text { Quality of originality }_{\text {subtest }}=\sum \text { originalitytask } / \sum \text { fluency }_{\text {task }}
\end{gathered}
$$

The fluency value in the formula represents the number of answers given to the task. This correlates with originality on a high, $\mathrm{r}=.85-.90$ level and does not carry information on its own. Each answer gets its originality value on a scale of 1-10 according to the following formula:

$$
\text { Originality }_{i 1}=10 \times(1-p)^{12}=10 \times\left(1-\left(\text { frequency of answer }_{\text {category }} / \text { frequency of answer }_{\text {total }}\right)\right)^{12}
$$

As a function of total answers given, scoring categories were established based on a multi-faceted definition of originality. Novel, unique, or unusual answers and ideas were categorized as original. Complexity of the content and compliance with cultural values were also considered (Runco, 2014). In case of the Function searching subtest the utility of the idea was also taken into account. The formula based on the exponential transformation of response frequency and the category classification based on the content together enable complex, constructive, seldom occurring answers to get a high score instead of extreme, autotelic novelty.

\section{RESULTS}

\subsection{ANALYZING CONSTRUCT VALIDITY AND RELIABILITY OF MONDALK TEST}

We focused on the organization of the test's originality values and we hypothesized a related, partly domain-specific factor structure. A three-factor model fits this assumption, where the originality values of the tasks of a subtest are linked by strong regression weights, and at the same time, the summed 
originality values of the subtests have high covariance. The result of the confirmatory factor analysis (CFA) reinforcing the construct validity of the test is shown in Figure 1.

Figure 1. Confirmatory factor analysis of MONDALK Test

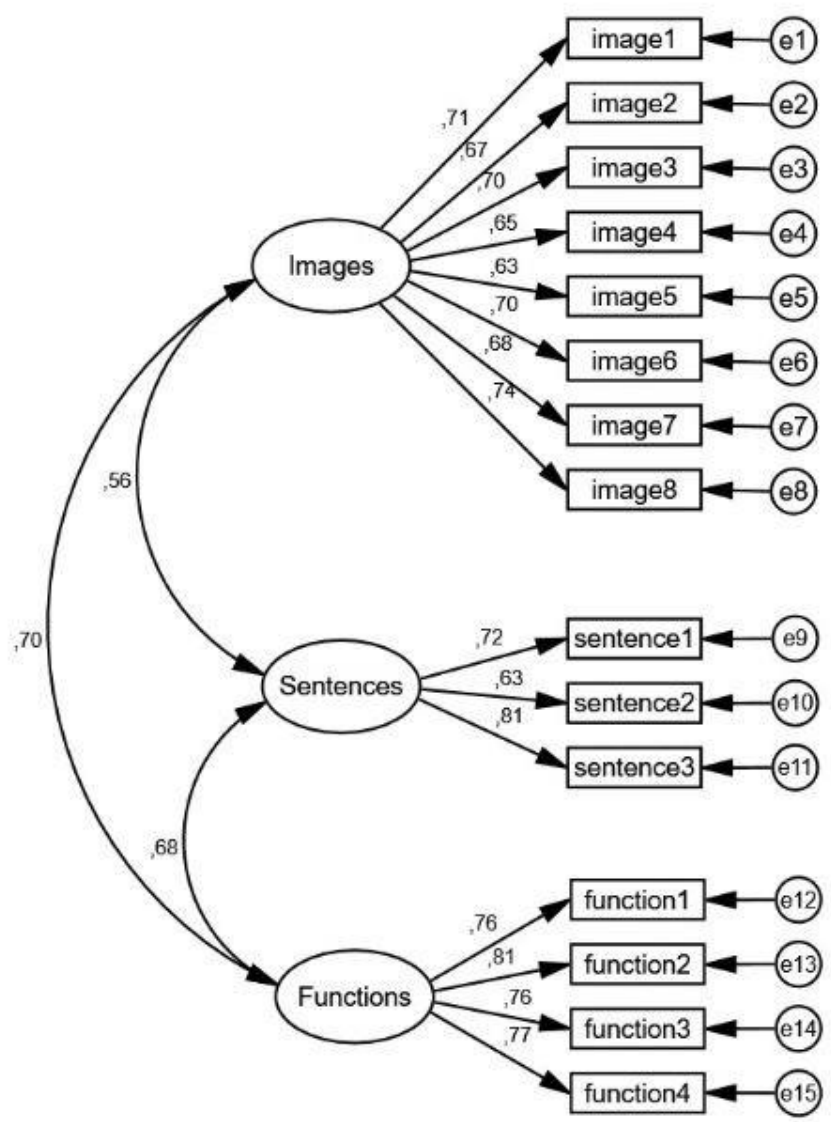

Note: Variables contain originality values. Meaning of abbreviated subtest names: Images - Image meanings, Sentences Sentence generation, Functions - Function searching

According to the CFA the A and B versions of the test show a similar factor structure. Model fit parameters of version $\mathrm{A}: \mathrm{n}=606, \chi^{2} / \mathrm{df}=1,49, \mathrm{TLI}=.984, \mathrm{CFI}=.988, \mathrm{RMSEA}=.029$; of version $\mathrm{B}$ : $\mathrm{n}=613, \chi 2 / \mathrm{df}=1.62, \mathrm{TLI}=.974, \mathrm{CFI}=.981, \mathrm{RMSEA}=.032$. The levels of model fit parameters are good, therefore it can be stated that the three subtests incorporate different domains of divergent thinking, but show the same construct. Spearman correlations of originality and quality of originality within the subtests of Image meanings, Sentence generation and Function searching in version A are: .785, .515 and .617 ; in version B: .701, .488 and .583, respectively. The values of the correlation between the measures of originality and quality of originality not only show that the measures belong to the same construct but they also signal a person's creativity in different ways. Therefore, it is important to create separate test norms and specific interpretation for them when identifying abilities.

Reliability measures of the versions of the test and the subtests are: Image meanings: Cronbach's $\alpha>=.889$, Sentence generation Cronbach's $\alpha>=.858$, Function searching: Cronbach's $\alpha>=.836$. Each 
value satisfies the requirements of the inner consistency of test items well. CFA results and reliability values presented by subtests confirm that identifying high creative ability is possible through a profile analysis of the measures of the subtests, instead of a single total score of the originality or the quality of originality measure. Profile analysis can be carried out in three related, but relatively independent domains of information organization: visual, linguistic and productivity-based domains. The tasks of Image meanings include visual patterns, and the quality of the verbal answers can be evaluated by relating them to the visual content. The quality of the answers given to Sentence generation subtest is determined by the novelty and unusual combination of the content of the verbal-linguistic items. To reach a high score with an answer in the Function searching subtest, it is hypothesized that beyond relying on imagination, the task requires multiple monitoring of the object given in the test situation, therefore a strong activity of executive functions is necessary (Benedek et al., 2014).

\subsection{IS MONDALK TEST BIASED AGAINST SOCIALLY DISADVANTAGED STUDENTS AND THOSE AT THE RISK OF SCHOOL DROPOUT?}

An unavoidable aspect of test evaluation criteria is informing test users how the test works with special groups of students (Rimm et al., 2008). High risk groups regarding school career are socially disadvantaged (SD) students and those at the risk of school dropout. In the practice of identifying gifted in schools, determination of cut-off criterion for high abilities can differ depending on models of giftedness or available gifted programs (Kaufman et al., 2009). Stricter cut-off points usually utilize the $90^{\text {th }}$ percentile (identifying the top $10 \%$ as gifted), a broader application of the criterion use above $80^{\text {th }}$ percentile (top 15-20\%).

If a $90^{\text {th }}$ percentile cut-off point is used for the subtests of MONDALK, the lowest representation of SD students is in the Sentence generation subtest (Figure 2.), although this difference is not significant, but shows a strong tendency $(\chi 2=3.17, \mathrm{p}=.075)$. 
Figure 2. Percent of high creative ability students using a $90^{\text {th }}$ percentile cut-off point criterion of Originality as a function of social disadvantage

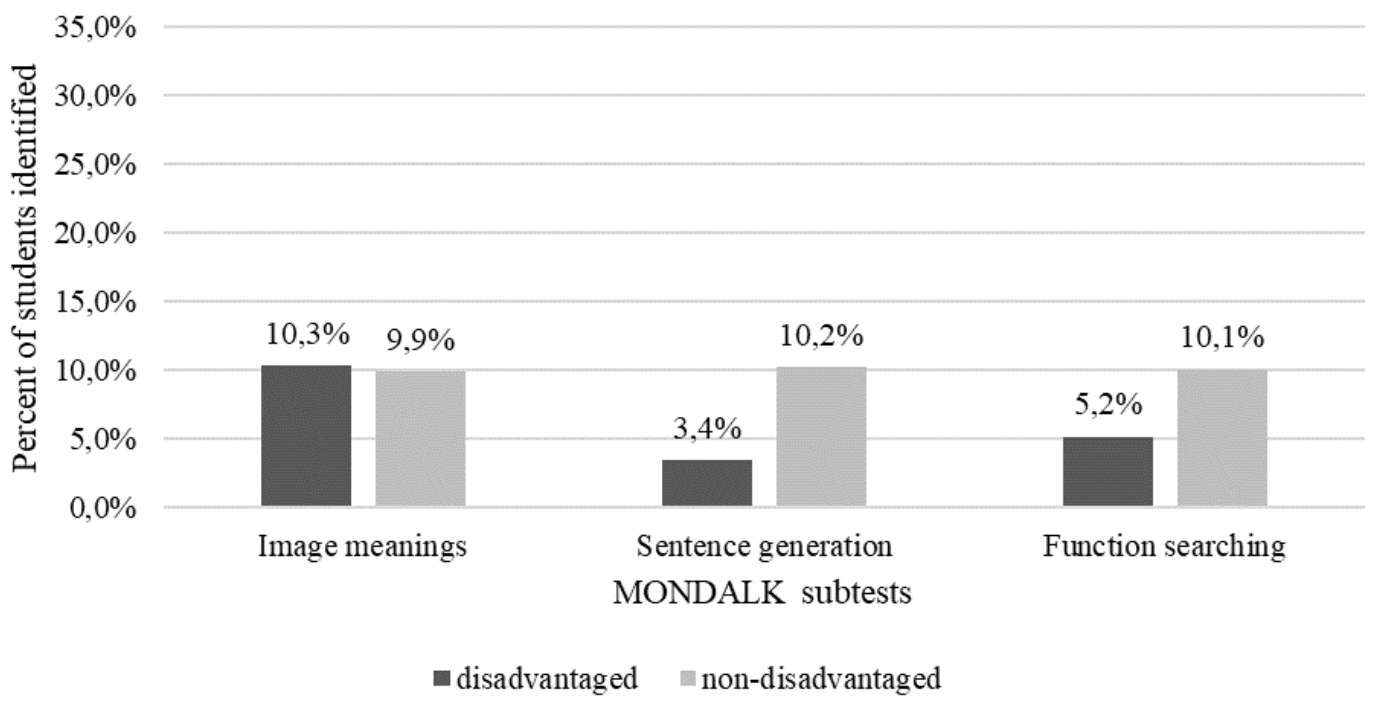

Note: Socially disadvantaged learners: $\mathrm{N}=58$, non-socially disadvantaged learners: $\mathrm{N}=1161$.

If an $80^{\text {th }}$ percentile cut-off criterion is used for Originality (Figure 3.), representation of SD students among students of high creative abilities improves markedly. In the Image meanings subtest, SD students are overrepresented (9\% more than the expected $20 \%$ representation). The differences seen in the figures are not significant. Using an $80^{\text {th }}$ percentile cut-off point, equity for SD students to be enrolled into gifted programs is ensured.

Figure 3. Percent of high creative ability students using an $80^{\text {th }}$ percentile cut-off point criterion of Originality as a function of social disadvantage

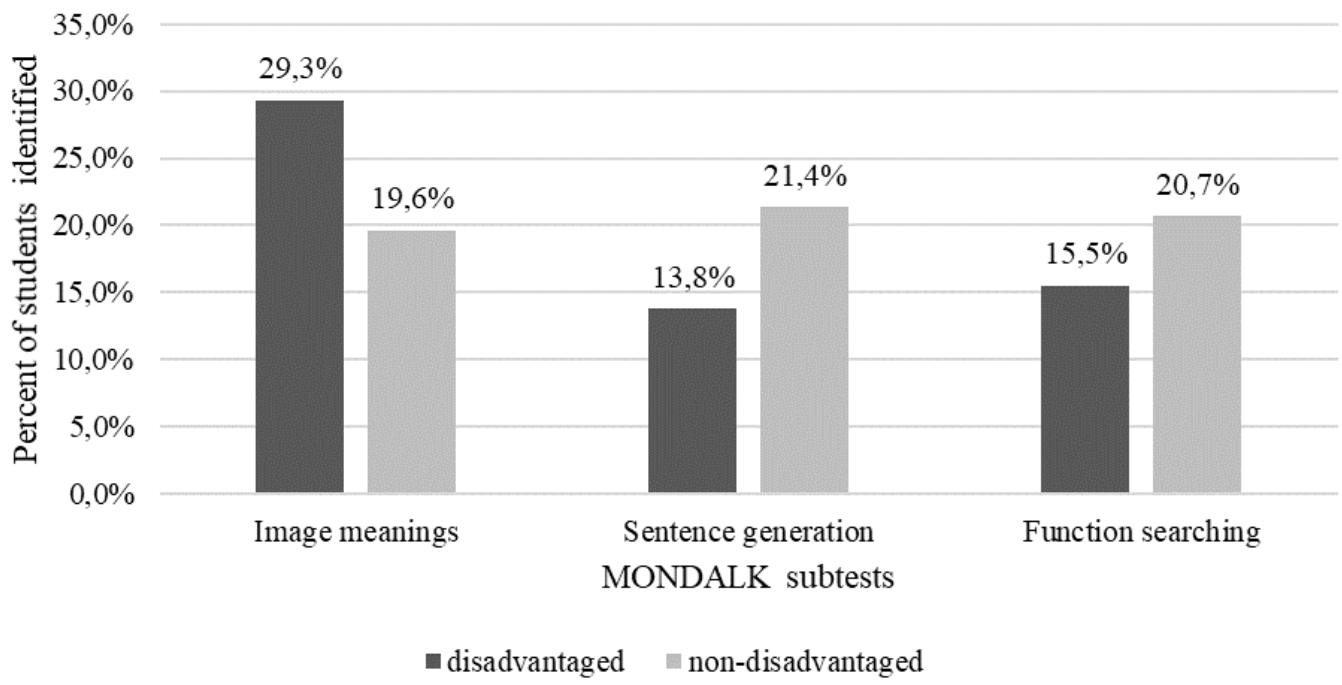

Note: Socially disadvantaged learners: $\mathrm{N}=58$, non-socially disadvantaged learners: $\mathrm{N}=1161$.

When examining the equitable opportunities of the 84 students with low achievement at risk of becoming a school dropout, we find that using the $90^{\text {th }}$ percentile cut-off criterion of the Originality 
measure, these students are unlikely to be classified as having high creative ability (Figure 4.). Differences are significant regarding all subtests $(\chi 2>=4.5, \mathrm{p}<.05)$.

Figure 4. Percent of high creative ability students using a $90^{\text {th }}$ percentile Originality cut-off criterion as a function of achievement

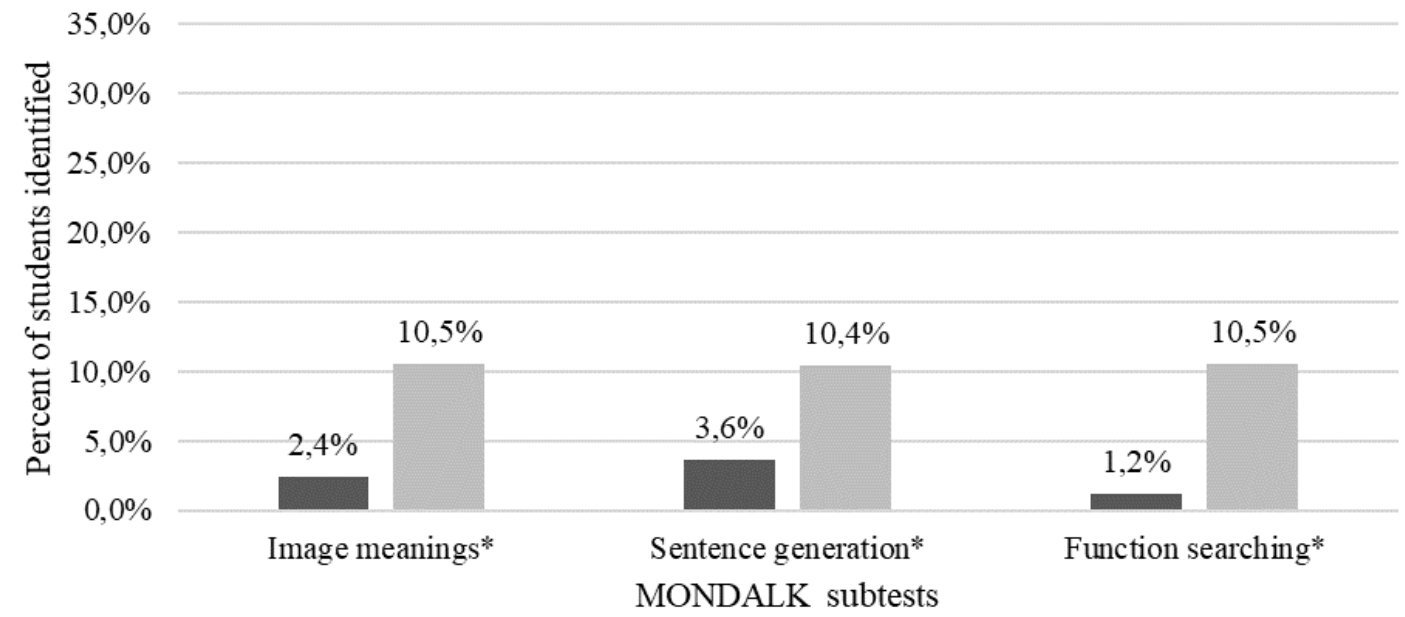

घ low achievement $\quad$ high achievement

Note: Low achievement is an overall grade average below or equal to 2.5 on a 5-point scale for at least one semester, while high achievement is defined as an overall grade average above 2.5 .

low achievement: $\mathrm{N}=84$, high achievement: $\mathrm{N}=1135$. *The difference is significant at $\mathrm{p}<0.05$.

An equitable solution cannot be achieved in case of students at risk of school dropout the same way as with SD students by simply lowering the cut-off point of Originality to $80^{\text {th }}$ percentile. The desired outcome may be achieved by utilizing an $80^{\text {th }}$ percentile cut-off criterion regarding the Quality of Originality measure (Figure 5.).

Figure 5. Percent of high creative ability students using an $80^{\text {th }}$ percentile cut-off criterion of Quality of Originality as a function of achievement

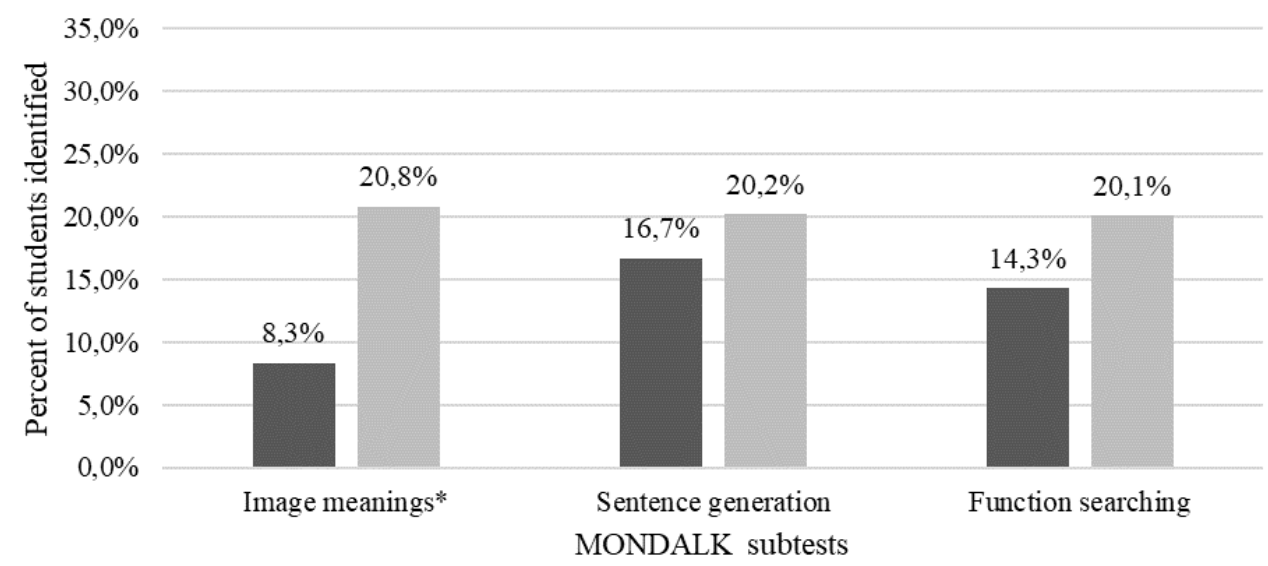

- low achievement $\quad$ high achievement

Note: Low achievement is an overall grade average below or equal to 2.5 on a 5-point scale for at least one semester, while high achievement is defined as an overall grade average above 2.5. 
low achievement: $\mathrm{N}=84$, high achievement: $\mathrm{N}=1135$. $*$ The difference is significant at $\mathrm{p}<0.05$.

Figure 5. shows that Image meanings subtest gives limited chances for underachievers to be identified, the difference is significant $(\chi 2=3.78, \mathrm{p}<.05)$. However, applying an $80^{\text {th }}$ percentile cut-off criterion of the Quality of Originality measure for the other two subtests ensures that underachievers are identified for their high abilities.

\section{DISCUSSION AND SUMMARY}

Using an $80^{\text {th }}$ percentile (top 20\%) cut-off criterion of the Originality measure in gifted identification, SD students are overrepresented in the Image meanings subtest and their representation improves markedly in subtests Sentence generation and Function searching. Therefore, the use of an $80^{\text {th }}$ percentile cut-off criterion is suggested in gifted identification of SD students.

The application of the $80^{\text {th }}$ percentile (top 20\%) cut-off criterion in gifted identification only ensures a fair representation of students at the risk of school dropout if the Quality of Originality measure is used for every subtest. Surprisingly, better results are seen in subtests using a verbal linguistic as opposed to visual stimuli. A possible explanation is, that those scoring high on Quality of Originality tend to give fewer answers than the average, and the first answer of a task with visual stimuli is more easily accessible from the long term memory, but less original, as compared to tasks based on verbal stimuli. Identification of high creative abilities utilizing the Originality measure is important in case of students at the risk of school dropout, but with this special group, only using the Quality of Originality measure will result in an equitable number of high creative ability identifications.

\subsection{THE NEED FOR DEVELOPMENTAL APPROACH IN GIFTED IDENTIFICATION}

To develop the abilities of young gifted people, it is important to identify creative thinking as a high functioning ability with tests in situations where students' low performance in the given learning environment result in different perceptions of their abilities. In line with research reviewed by Kim (2005) correlations between school achievement and creativity results measured by MONDALK Test are low: Image meanings: $r=.193$, a Sentence generation: $r=.194$, Function searching: $r=.349$. Creative ability identified with tasks needing divergent thinking is completely different from school achievement, the latter mostly accomplished through conventional, mostly convergent school tasks. To succeed in gifted development, after identifying high creative ability, a learning environment supporting gifted development will have to enhance task motivation (García et al., 2021b). Over and above these attention should be given to decreasing disadvantages and transforming learner abilities into skills, achievement products. 


\section{REFERENCES}

Amabile, T. M. (1983). The social psychology of creativity: A componential conceptualization. Journal of Personality and Social Psychology, 45(2), 357-376.

https://doi.org/10.1037/0022-3514.45.2.357

Amabile, T. M. (2013). Componential theory of creativity. In E. H. Kessler (Ed.), Encyclopedia of Management Theory (pp. 134-139). Sage Publications. http://dx.doi.org/10.4135/9781452276090

An, D., \& Runco, M. A. (2016). General and domain-specific contributions to creative ideation and creative performance. Europe's Journal of Psychology, 12(4), 523-532.

https://doi.org/10.5964/ejop.v12i4.1132

Baer, J. (2011). How divergent thinking tests mislead us: Are the Torrance Tests still relevant in the 21st century? The Division 10 debate. Psychology of Aesthetics, Creativity, and the Arts, 5(4), 309-313. https://doi.org/10.1037/a0025210

Barkóczi, I., \& Zétényi, T. (1981). A kreativitás vizsgálata [Testing Creativity]. Országos Pedagógiai Intézet.

Benedek, M., Jauk, E., Sommer, M., Arendasy, M., \& Neubauer, A. C. (2014). Intelligence, creativity, and cognitive control: The common and differential involvement of executive functions in intelligence and creativity. Intelligence, $46,73-83$.

https://doi.org/10.1016/j.intell.2014.05.007

Dixon, J. (1979). Quality versus quantity: The need to control for the fluency factor in originality scores from the Torrance tests. Journal for the Education of the Gifted, 2(2), 70-79.

Gagné, F. (2004). Transforming gifts into talents: the DMGT as a developmental theory, High Ability Studies, 15(2), 120-147. https://doi.org/10.1080/1359813042000314682

García, S. G., Nicolás, A. H., Cano, M. G., \& Alonso, J. M. R. (2021a). Giftedness in the students of the second cycle of childhood education. Intervention strategies in the classroom. South Florida Journal of Development, 2(1), 164-175. https://doi.org/10.46932/sfjdv2n1-015

García, S. G., Nicolás, A. H., Cano, M. G., \& Alonso, J. M. R. (2021b). Gamification in the childhood education classroom. South Florida Journal of Development,2(1), 623-632. https://doi.org/10.46932/sfjdv2n1-045

Geiser, C., Mandelman, S., Tan, M., \& Grigorenko, E. L. (2016). Multitrait-Multimethod Assessment of Giftedness: An Application of the Correlated Traits-Correlated (Methods-1) Model. Structural Equation Modeling: A Multidisciplinary Journal, 23(1),76-90. https://doi.org/10.1080/10705511.2014.937792

Heausler, N. L., \& Thompson, B. (1988). Structure of the Torrance Tests of creative thinking. Educational and Psychological Measurement, 48(2), 463-468. https://doi.org/10.1177/0013164488482021

Kaufman, J. C., Beghetto, R. A. (2009). Beyond Big and Little: The Four C Model of Creativity. Review of General Psychology, 13 (1), 1-12. https://doi.org/10.1037/a0013688 
Kaufman, J. C., Kaufman, S. B., Beghetto, R. A., Burgess, S. A., \& Persson, R. S. (2009) Creative giftedness: Beginnings, developments, and future promises. In L- V- Shavinina (Ed.), International handbook on giftedness (pp. 585-598). Springer. https://doi.org/10.1007/978-1-4020-6162-2

Kim, K. H. (2005). Can only intelligent people be creative? A meta-analysis. Journal of Secondary Gifted Education, 16(2-3), 57-66. https://doi.org/10.4219/jsge-2005-473

Kim, K. H., Cramond, B., \& Bandalos, D. L. (2006). The latent structure and measurement invariance of scores on the Torrance Tests of Creative Thinking-Figural. Educational and Psychological Measurement, 66(3), 459-477. https://doi.org/10.1177/0013164405282456

Krumm, G., Filipppetti, V. A., Lemos, V., Koval, J., \& Balabanian, C. (2016). Construct validity and factorial invariance across sex of the Torrance Test of Creative Thinking-Figural Form A in Spanishspeaking children. Thinking Skills and Creativity, 22, 180-189. https://doi.org/10.1016/j.tsc.2016.10.003

Lau, S., \& Cheung, P. C. (2010). Creativity assessment: Comparability of the electronic and paper-andpencil versions of the Wallach-Kogan Creativity Tests. Thinking Skills and Creativity, 5(3), 101-107. https://doi.org/10.1016/j.tsc.2010.09.004

Paulus, P. B., Kohn, N. W., \& Arditti, L. E. (2011). Effects of quantity and quality instructions on brainstorming. The Journal of Creative Behavior, 45(1), 38-46.

https://doi.org/10.1002/j.2162-6057.2011.tb01083.x

Pásztor, A., Molnár, G., \& Csapó, B. (2015) Technology-based assessment of creativity in educational context: the case of divergent thinking and its relation to mathematical achievement. Thinking Skills and Creativity, 18, 32-42.

https://doi.org/10.1016/j.tsc.2015.05.004

Rimm, S. B., Gilman, B. J., \& Silverman, L. K. (2008) Non-traditional applications of traditional testing. In J. VanTassel-Baska (Ed.), Alternative assessments with gifted and talented students (pp.175-202). Prufrock Press Inc.

Runco, M. A. (1986). The discriminant validity of gifted children's divergent thinking test scores. Gifted Child Quarterly, 30(2), 78-82.

https://doi.org/10.1177/001698628603000207

Runco, M. A. (2014). Creativity: Theories and themes: Research, development, and practice (2nd ed.). Elsevier Academic Press.

Runco, M. A., \& Acar, S. (2012). Divergent thinking as an indicator of creative potential. Creativity Research Journal, 24(1), 66-75.

https://doi.org/10.1080/10400419.2012.652929

Said-Metwaly, S., Van den Noortgate, W., \& Kyndt, E. (2017). Approaches to measuring creativity: a systematic literature review. Creativity. Theories-Research-Applications, 4(2), 238-275. https://doi.org/10.1515/ctra-2017-0013

Torrance, E. P. (1990). Torrance Test of Creative Thinking. Scholastic Testing Service.

Wallach, M. A., \& Kogan, N. (1965). Modes of thinking in young children: A study of the creativity intelligence distinction. Holt, Rinehart \&Winston. 